\title{
COMUNICAÇÃo
}

\section{AIDS - UM ENFOQUE ÉTICO-POLÍTICO}

\author{
Genival Veloso de França
}

Acredito que, em nenhum momento da existência humana, jamais houve um inimigo biológico tão poderoso, capaz de trazer mais desafios e de confundir a opinião pública como a Síndrome da Imunodeficiência Adquirida (AIDS). Certamente, ainda vamos permanecer atônitos e perplexos por muito tempo, mesmo depois da descoberta do seu tratamento, porque inúmeras são as implicações dessa nova ordem no contexto das relações sociais. Nenhuma doença trouxe, no seu conjunto, tanta complexidade e inquietação quanto a AIDS, seja no seu aspecto epidêmico, moral ou imunológico, seja no seu caráter incurável e letal. Pelo menos, é assim que ela é vista por muitos. E o pior: toda vez que discriminamos as vítimas, fortalecemos mais e mais a doença.

No entanto, a partir do instante de uma reflexão mais atenta, começamos a enxergar uma multidão de fatos que alucina e dá à AIDS um rótulo maldito e fatal. Mas, tão contraditório, a ponto de não existir ainda uma resposta imediata para justificar o seu aparecimento, se ela é ou não uma doença atual e qual a razão de sua trágica rapidez. Seria ela uma nova doença tão ao gosto das mentes especulativas ou apenas a reorganização sistemática de uma propedêutica sobre o que já existia?

Mesmo que a intuição científica leve a crer que estamos marchando para a cura da AIDS, muitas verdades médicas ainda não foram descodificadas e o preconceito continua a crescer como uma avalanche arrasadora. $O$ perigo de tal avanço é que essa doença saia do corpo dos pacientes e permaneça na imaginação de todos, estigmatizada pela discriminação odiosa e fantasiada pelo modismo que contamina os doentes, a sociedade es próprios médicos. O risco, portanto, é se transformar a AIDS numa fiç̧ão, ou criar-se uma ideologia política autoritária capaz de promover o medo como controle social mais rigoroso.

Quando se disse, no início, que ela seria uma

Prof. de Medicina Legal e Deontologia Médica da Universidade Federal da Paraiba, João Pessoa, PB.

Recebido para publicação em $02 / 07 / 93$. entidade dos homossexuais, era de fato dos homossexuais porque apenas neles se procurou a doença. Depois, afirmou-se que podia ser ainda dos consumidores de drogas injetáveis e passou a ser igualmente deles. Agora, é também dos heterossexuais, e a sua incidência, segundo essa visão, é cada vez maior. Já se acredita que, sendo a AIDS uma virose clássica e tendo como via principal de contágio o ato sexual, e admitindo-se que as pessoas são, em sua maioria, heterossexuais, no futuro, a prevalência dos pacientes e infectados, seria de heterossexuais.

$O$ fato é que hoje, em toda parte, os portadores de AIDS enfrentam uma situação constrangedora. Sofrem o horror de uma doença que os estigmatiza no convívio social e os avilta na luta pelos meios de sobrevivência. São doentes marginais do desprezo e do abandono, mesmo dos que lhes são próximos. Negam-lhes tudo: $o$ afeto, a estima, a solidariedade e, até, o direito de morrer com dignidade.

Vejamos algumas situações:

\section{A esterilização dos HIV - positivos}

Qualquer que seja o andamento da discussão que favorece a esterilização humana, como forma de inserção numa política de planejamento demográfico, não existe nenhuma justificativa de ordem ética ou legal, capaz de legitimar essa prática em pessoas portadoras de sorologia positiva para o vírus da imunodeficiência humana (HIV), porque qualquer forma de insinuação eugênica traz sempre o ranço do constrangimento e as marcas da repugnância.

Mais grave do que esterilizar um homem ou uma mulher, hígido e capaz, é invadir a intimidade de um ser humano, aviltando-o na sua dignidade e mutilandoo nas suas funções, unicamente com o sentido de privar a sociedade da responsabilidade, da vigilância e dos cuidados, pelo fato de ser portador - mais de um estigma do que de uma doença, deixando bem claro o indisfarçado preconceito contra esses indivíduos, expostos quase sempreàs crueldades de uma sociedade hipócrita e egoísta. 


\section{O aborto da mulher infectada pelo HIV}

Ainda que exista o risco da contaminação ou de doença do feto, não se permite legalmente nem se considera eticamente defensável a prática do abortamento da mulher infectada pelo HIV. O Código de Ética Médica em vigor, em consonância com a legislação penal brasileira, só admite o aborto em duas situações: para salvar a vida da gestante ou nos casos de gravidez resultante de estupro.

Pelo fato de se tratar de um matéria sem resposta definitiva, no que diz respeito à influência da sorologia positiva no processo gestacional e da própria saúde do feto, minha opinião é que não existe nenhum argumento ético, jurídico ou técnico, capaz de fundamentar a interrupção de uma gravidez numa portadora de HIV-positiva ou mesmo de uma doença de AIDS, a não ser que suas condições de saúde sejam agravadas pela gestação, que cessada a gravidez cesse o perigo e que não haja outro meio de salvar-lhe a vida.

\section{A gestante HIV-positiva}

Ainda que exista uma possibilidade de morte precoce, de sofrimento oriundo da doença, de riscos de contaminação do feto e de informações desistimuladoras, esses fatos nem sempre têm desanimado as mulheres HIV-positivas na sua decisão de engravidar. Não se sabe ainda, por exemplo, a época exata da contaminação - se durante a vida intra-uterina ou se no momento do parto, mas, uma coisa é certa: a gravidez, nesta hipótese, não melhora nem piora as condições imunológicas das gestantes.

Assim, seja qual for o entendimento que se tenha a respeito da transmissão, das formas de infecção e do mecanismo de contágio, o médico não pode impedir essa mulher de engravidar e ter seu filho, se esse é o seu desejo. Mas, tão-somente, oferecer-lhe todos os meios e recursos necessários e disponíveis para uma gestação nestas condições. Nenhum médico e nenhuma instituição de saúde pode negar-lhe assistência, pois isso é um ditame ético exigido a todos aqueles que professam a medicina, mesmo que possam ter um entendimento diverso sobre a questão, no seu plano conceitual e doutrinário.

Ninguém discute aqui o valor e a procedência do diagnóstico precoce da infecção, permitindo à mulher utilizar-se de processos contraceptivos capazes de evitar uma gravidez em tal estado, ou como forma de orientação de cuidados pré e pósnatais, no propósito de reduzir ao máximo o risco da contaminação do feto ou do recém-nascido, além dos procedimentos necessários ao infante eventualmente infectado.

\section{O sigilo como instrumento social}

É imperioso lembrar que o segredo médico é um direito do paciente, como forma definitiva de conquista da cidadania e somente a ele cabe abrir mão desse privilégio. A não ser naquilo que o Código de Ética Médica desobriga: por justa causa ou por dever legal. O paciente infectado pelo HIV não foge a essa regra.

Se o paciente, neste particular, manifesta o desejo de que seus familiares não tenham conhecimento de suas condiçōes, ainda assim deve o médico respeitar tal decisão, persistindo essa proibição de quebra de sigilo mesmo após a sua morte. No entanto, é providencial que se exija do portador do HIV-positivo a designação de uma pessoa de sua inteira confiança para servir de intermediário entre ele e quem o assiste, e que o paciente colabore no sentido de cientificar aos seus parceiros sexuais ou membros de grupo de uso de drogas pesadas, no intuito de evitar a propagação do mal. Por outro lado, é obrigatória a notificação de todos os casos suspeitos ou com diagnóstico confirmado de AIDS. Não deve haver notificação dos casos de pessoas simplesmente infectadas pelo HIV.

Desse modo, só será permitida a quebra do sigilo profissional quando houver expressa autorização do paciente ou de seus responsáveis; por dever legal, nos casos de notificação compulsória à autoridade sanitária ou em preenchimento de atestados de óbito de portadores de AIDS; ou, por justa causa, nas situações de proteção da vida e da saúde de terceiros - membros de grupos de uso de drogas injetáveis ou comunicantes sexuais, quando o próprio paciente recursar-se a fornecer-lhes informações quanto a sua condição de infectado.

Se os portadores de HIV confiarem na preservação do sigilo das informações prestadas às equipes multiprofissionais que cuidam desses casos, 
e que somente na condição de doentes de AIDS haveria comunicação aos setores sanitários responsáveis, além da certeza do respeito a sua privacidade, estaria resolvida, em parte, a questão dos exames periódicos voluntários, contribuindo de forma significativa para o controle e a avaliação do quadro epidemiológico.

\section{A inconveniência dos testes pré-admissionais}

Uma das formas de preconceito mais evidente, na relação com possíveis portadores do HIV, é a solicitação de exames pré-admissionais que se vem impondo como condição de ingresso no trabalho, na escola e, até mesmo, no internamento hospitalar, na espectativa de surpreender indivíduos sorologicamente positivos.

Entendo que não existe qualquer justificativa técnica ou científica para tais exames. Quem necessita saber sobre esses resultados são os próprios indivíduos e as autoridades sanitárias que organizam suas campanhas e medem a extensão do problema. Agindo-se de tal maneira contra os soro-positivos além dos despropósitos ético e científico, o critério é humilhante e contrário aos interesses sociais, pois desagrega $o$ indivíduo, empurrando-o para a marginalidade sem as possibilidades de trabalho, sem a assistência médica e sem as condições financeiras que favoreçam sua sobrevivência.

Ninguém discute o direito dos empregadores admitirem quem eles queiram. Todavia, os exames pré-admissionais devem ser feitos no sentido de proteger o trabalhador ou o funcionário público, e nunca como manobra vexatória e descabida, muitas vezes até fraudulenta, quando tais exames são feitos sem o conhecimento prévio dos candidatos. $O$ pedido de testes, simplesmente para flagrar um ou outro portador do HIV, é imoral, constrangedor e atentório à dignidade humana, pois não atende aos interesses do trabalho e do trabalhador, mas, tãosó, no sentido de discriminar esses soro-positivos.

No que se refere à posição dos médicos de empresas ou de juntas oficiais, todas as informações obtidas sobre esse assunto, devem ser transinitidas apenas ao paciente. Qualquer informação sobre o empregado ao empregador, limitar-se-á à aptidão ou à não aptidão do trabalhador, e se temporária ou permanente para o desempenho de determinadas funções. A realização de testes sorológicos por imposição do empregador não encontra amparo técnico, científico ou moral, sendo esse assunto do interesse da autoridade sanitária. Até mesmo o poder público reconheceu seu equívoco, ao decidir, na Portaria Interministerial $\mathrm{n}^{\circ} \cdot 869$, de 11 de agosto de 1992, dos Ministérios da Saúde e do Trabalho e da Administração, "proibir, no âmbito do serviço público, a exigência de testes de detecção de vírus da imunodeficiência adquirida, tanto nos testes préadmissionais quanto nos exames periódicos de saúde", considerando que a sorologia positiva não acarreta prejuízo da capacidade laborativa do seu portador, que os convívios social e profissional com portadores do vírus não configuram situações de risco, que a solidariedade e o combate à discriminação são fórmulas que a sociedade dispõe para minorar o problema e que essas situações devem ser conduzidas segundo os preceitos da ética e do sigilo.

O Conselho Federal de Medicina determinou, através da Resolução CFM n ${ }^{\text {o. }} 1.359 / 92$, que é vedada a realização compulsória da sorologia para HIV, em especial como condição necessária a internação hospitalar, pré-operatório, ou exames pré-admissionais ou periódicos e, ainda, em estabelecimentos prisionais.

Por fim, é bom que se enfatize ser a identificação de pacientes HIV-positivos em internamento hospitalar, uma estratégia sem muita sustentação moral e nenhuma argumentação técnica, pois, na urgência, onde os aludidos riscos seriam mais evidentes, não haveria tempo para esperar o resultado sorológico. Haveria ainda o risco dos pacientes com viremia e sorologicamente negativos, e os casos dos que se negassem a tais exames. Os pacientes, por sua vez, notadamente os submetidos a procedimentos invasivos, teriam também o direito de exigir, com muito mais razão, o teste do médicos. O que se deve exigir urgentemente é um nível sério de cuidados, na proteção de todos os profissionais de saúde, com enfoque para aqueles casos onde a contaminação sanguínea seja possível. No entanto, se alguma instituição quiser exigir a triagem sorológica dos pacientes não emergenciais, para que esse modelo venha ser eticamente discutível, é necessário que o exame seja voluntário e informado, que o paciente ao não aceitar o teste possa ser tratado sem nenhuma restrição, e que o paciente positivo tenha garantia do sigilo em relação ao resultado do exame e não 
sofra qualquer prejuízo na qualidade da assistência requerida.

\section{O problema do menor infectado em estabelecimentos correcionais}

Das tantas complexidades do problema, certamente, a mais complexa é a do posicionamento a ser adotado pela equipe médica, em face da solicitação de autoridade judicial ou administrativa, sobre o fornecimento de dados relativos a menores infratores e detentos do sistema correcional, portadores de sorologia positiva para o HIV.

Em primeiro lugar, o médico não deve revelar às autoridades administrativas dos sistemas correcionais a identidade dos menores infratores com sorologia positiva. Não estaria justificada a quebra do sigilo pela suposta necessidade de adoção de medidas profiláticas, pois de nada adiantaria tal identificação, quando se sabe não existir nenhum procedimento que possa trazer benefícios ou que respeite à dignidade do menor, aumentando, isso sim, os riscos de segregação e de hostilidade. O que se deve fazer urgentemente, é melhorar as condições do atendimento nessas instituições, hoje tão precárias e desumanas.

Depois, acho conveniente revelar o fato aos pais ou aos seus responsáveis legais - no caso em tela, o juiz - por entender que aquele menor não tem a capacidade de avaliar seu problema e de conduzirse por seu próprios meios para solucioná-los, como recomenda o artigo 103 do Código de Ética Médica.

E, por fim, acredito ser necessária a revelação do segredo à equipe multidisciplinar, que trata também do menor, por considerar que a solução do problema não é da exclusiva competência médica, mas de tantos outros profissionais, os quais, também, sujeitos à obrigatoriedade do sigilo.

\section{A postura do médico infectado}

As informações referentes aos mecanismos de contágio, disseminação e formas de infecção pelo HIV não devem ficar restritas à população. Devem também ser repassadas aos médicos e aos profissionais de saúde como um todo.

O médico infectado, como todos os pacientes, tem o direito à privacidade, ao sigilo e ao respeito que toda pessoa merece, não se podendo privar dele suas atividades no convívio social e do trabalho, respeitadas, é claro, as condições que seu estado de saúde permite e o tipo de atividade exercida.

Por outro lado, não se pode aceitar as recomendações do Centro de Controle de Doenças dos Estados Unidos (CDC), a partir de possibilidades remotas de transmissão do HIV, quando trata dos profissionais de saúde infectados. Em primeiro lugar, não há razões de ordem técnica ou moral para a realização sistemática e compulsória de sorologia anti-HIV em profissionais mais expostos, pois o risco de contaminação em alguns casos é quase nulo. Como também não existe a necessidade da comunicação aos pacientes sobre a condição sorológica dos médicos infectados, que possam se envolver nos chamados procedimentos invasivos (atos sujeitos a risco de contaminação por perfuração acidental percutânea do profissional, através de contato do seu sangue com tecidos do paciente). E, muito menos, o impedimento de profissionais infectados de trabalharem normalmente em tarefas compatíveis com as suas condições de saúde e com a modalidade de trabalho exercido.

No entanto, recomenda-se que o médico portador de sorologia positiva para o HIV, sponte sua, evite ou tome determinados cuidados com certos atos, principalmente nos procedimentos invasivos ou na manipulação de instrumental cortante ou perfurante capaz de passar sangue acidentalmente para o paciente, mesmo tendo em conta a probabilidade mínima de contaminação nesses casos. Não se considera errado o fato da direção do corpo clínico discutir, caso-a-caso, a participação de cada profissional reconhecido como infectado, a partir do momento em que se evidencia atitudes mais imprudentes por parte do médico em questão, pois deixar o problema sem nenhum controle também seria uma conduta reprovável.

Em suma, o médico infectado pelo HIV, como qualquer outra pessoa, deverá ter sua privacidade respeitada, não existindo a necessidade dele informar sobre sua situação. Todavia, havendo acidentes em procedimentos invasivos, o médico que conhece seu estado sorológico positivo está obrigado eticamente a levar o fato ao conhecimento das equipes de suporte e orientação, como, também, é dever dessas equipes informarem o paciente sobre o possível risco e orientá-lo para os exames de praxe. Sendo o médico não-infectado e o paciente 
reconhecido como portador de sorologia positiva, havendo acidente em procedimento invasivo ou acidente com instrumental cortante ou ponteagudo, o médico tem de procurar aquelas equipes de orientação e submeter-se ao exame sorológico necessário.

\section{A postura do médico ante os doentes e infectados pelo HIV}

Nenhum médico pode recusar o atendimento profissional a pacientes portadores do vírus da imunodeficiência humana, pois essa assistência representa um imperativo moral da profissão médica. Assim se reporta em tom dogmático a Resolução CFM n ${ }^{\text {o. }} 1.359$, de 11 de novembro de 1992.

Levando em conta que a medicina é uma profissão voltada para a saúde do ser humano e da coletividade e deve ser exercida sem nenhuma forma de discriminação; que a AIDS continua avançando e mudando seu perfil epidemiológico quando agride os diferentes grupos populacionais; e que o impacto da doença é medonho e limita o paciente, vulnerando-o física, moral, social e psicologicamente, tem-se de admitir que a obrigatoriedade do atendimento há de ser extensiva a todas as instituições de saúde, sejam elas públicas, privadas ou ditas filantrópicas.

É preciso também que esse atendimento seja integral e compatível com as normas de bio-segurança recomendadas pela Organização Mundial de Saúde e pelo Ministério da Saúde, e, por isso, não se pode aventar qualquer forma de desconhecimento ou falta de condições técnicas para recusar a assistência. Essas instituições devem também propiciar a todos os profissionais de saúde condições técnicas para recusar a assistência. Essas instituições devem também propiciar a todos os profissionais de saúde condições dignas para o exercício da profissão, inclusive os recursos para a proteção contra a infecção, com base nos conhecimentos científicos disponíveis. A garantia dessas condições de atendimento é de responsabilidade do Diretor Técnico de cada estabelecimento de saúde.

Sobre os infectados pelo HIV, como já foi dito, o sigilo deve ser integralmente atendido e isso implica, entre outros, nos casos em que o paciente deseja que sua condição sorológica não seja revelada sequer aos familiares, continuando esse direito de manutenção do segredo, mesmo após a morte do assistido.

\section{As deficiências da legislação brasileira}

Partindo do princípio de que as questoes de saúde pública, primordialmente, representam um direito inerente à cidadania e uma irrecusável e fundamental obrigação do Estado, cabe, através de uma estratégia bem articulada junto ao Sistema Único de Saúde, uma atenção desdobrada à prevenção, ao diagnóstico e ao tratamento da AIDS, assim como uma abordagem mais séria em favor dos infectados pelo HIV.

Ninguém pode desconhecer que essa doença é uma entidade sorológica grave, de evolução rápida e caminhando quase sempre para a morte e que, face suas características epidemiológicas, tende a se transformar num sério problema de saúde pública, necessitando, também, de um encaminhamento que não deixe de contar com a participação de todos no seu controle e prevenção. Assim, é imperativo, antes de tudo, a participação democrática de todos os segmentos organizados e representativos da sociedade, a fim de pressionar o Estado que assuma, por decisão política, uma postura capaz de garantir a mais ampla cobertura sobre o problema.

Atualmente, muitos são os países que contam com normas específicas que regulam os direitos dos pacientes aidéticos e dos infectados, desde a proibição da rejeição de crianças sorologicamente positivas em escolas e creches, até a censura aos pedidos de testes para o HIV de pacientes em internamentos hospitalares.

Primeiro, é necessário yue se assegure a esses pacientes o acesso ao tratamento adequado, seja no ambulatório, no hospital ou no domicílio, incluindo nisso o fornecimento gratuito de medicamentos necessários e eficazes no tratamento da AIDS, aprovados pelo Ministerio da Saúde, afim de que essas ocorrências não se transformem em "casos de polícia”. Defendo também a idéia - embora criticada por alguns, que se estipule em cada hospital público ou privado, qualquer que seja sua especialidade, um número mínimo de leitos para tratamento desses pacientes, como forma de impedir que eles sejam rejeitados no internamento, por motivo de discriminação ou má vontade, mesmo sabendo da disponibilidade de leitos em nosso país. 
Advogo também a idéia de não se criar leitos destinados aos pacientes apenas infectados pelo HIV, que por ventura se internem nos hospitais para tratamento clínico ou cinúrgico, pois inevitavelmente seriam discriminados, dando-se, inclusive, oportunidade para a exigência dos testes préadmissionais, convertendo-se em expediente vexatório, hostilizante e segregador.

Nessa legislação deve ficar bem claro o direito que tem o paciente HIV-positivo da manutenção do sigilo médico, do respeito a sua privacidade, o impedimento de demissão sem justa causa do seu trabalho, a proibição da divulgação do seu nome ou de seus parentes em listas de resultados de exames e o direito de ter solicitados seus exames complementares quando pedidos pelos seus médicos assistentes.

É necessário ainda que se estipule espaços gratuitos nos meios de comunicação para divulgação desses interesses, a garantia dos pacientes aidéticos a todos os direitos trabalhistas, previdenciários e administrativos, além de assistência jurídica gratuita, acesso fácil e sem ônus ao tratamento dos hemofílicos como forma de prevenção à AIDS, o direito de receber visitas no hospital, de atendimento médico de urgência e de intercorrências clínicas e o de ter seu corpo velado em locais e condiçôes respeitosas, de acordo com a reverência que se deve à dignidade humana.

Outro fato é o da criação de serviços de diagnóstico gratuitos, estimulando-se assim os indivíduos ao auto-exame, sem nenhum ônus e cujos resultados sejam dados através de meios que não identifiquem o paciente, mantendo-se o respeito a sua privacidade. Essa seria uma forma de fazer com que um maior número de pessoas procurem esses exames.

Desistimular de uma vez por todas, não através de uma portaria, mas por meio de uma lei, a exigência de testes sorológicos para o HIV aos candidatos de concurso público ou ao acesso a empresas privadas, mesmo sabendo que um mandato de segurança, neste particular, seria um remédio tranquilo e eficaz.

Ficar, evidente, também, na legislação a proibição da exigência de testes compulsórios de sorologia para o HIV, como condição obrigatória de internamento hospitalar, pré-operatório, assim como nos indivíduos recolhidos em estabelecimentos penitenciários, ou de internação, antes de serem recolhidos. Isso não tem nenhum subsídio técnico ou científico, nem ajudaria em nada esse problema, a não ser fomentar a discriminação e a intolerância.

\section{Conclusão}

Se quisermos efetivamente lutar e vencer esse mal, devemos em primeiro lugar, não procurarmos explicações absurdas parajustificar nossa indiferença e as nossas limitações. Depois, ficar ao lado dos que estão sendo vitimados pelo flagelo da AIDS, neste instante tão amargo da história da humanidade.

Mesmo admitindo-se que essa doença seja, em parte, uma invenção nossa, ninguém pode escamotear a sua gravidade como entidade epidêmica, que agride o sistema imunológico de forma complexa, de assustadora rapidez e, até agora, incurável.

Urge, ainda - hoje, mais do que nunca - exigir do poder público as condições necessárias para tratar esses doentes com a dignidade que merece a condição humana, e fazer ver à própria sociedade que a única forma de vencer essa doença é protegendo e amparando os que estão sendo atingidos. E também denunciar todas as injustiças cometidas, mitigando as suas dores e compreendendo sua dolorosa solidão na hora do sofrimento e da morte.

Essas e outras epidemias passarão. Assim está escrito. O que fica é o perigo que o homem carrega consigo mesmo e a falta de conviç̧ão de que seu destino está inexoravelmente preso ao destino do outro. Se não, cabe uma mea culpa universal.

\section{REFERÊNCIAS BIBLIOGRÁFICAS}

1. CDC update. Transmission of HIV infection during invasive dental procedures. MMWR 40:377-381, 1991.

2. Chaui M. Repressão sexual - Essa nossa desconhecida. Brasiliense, São Paulo, 1985.

3. Foucault M. História da sexualidade. A vontade de saber. vol. I, Graal, Rio de Janeiro, 1984.

4. França GV. Direito Médico. Fundo Editorial Byk, São Paulo, 1992.

5. Levi G. Síndrome da imunodeficiência adquirida (AIDS). Revista da Associação Médica Brasileira vol. $31, n^{\circ} .9 / 10,1985$.

6. Sontag S. A doença como metáfora. Graal, Rio de Janeiro, 1984. 